\title{
DECADENCIA URBANA Y CLERO CONVENTUAL FEMENINO. SOBRE LA FUNDACIÓN DEL MONASTERIO DE SANTA ANA DE CHINCHILLA.
}

\section{URBAN DECLINE AND FEMALE CONVENTUAL CLERGY. ABOUT THE FOUNDATION OF THE MONASTERY OF SANTA ANA IN CHINCHILLA.}

CARlos Ayllón GutiérRez Instituto de Estudios Albacetenses «Don Juan Manuel» Albacete, España ayllongut@hotmail.com

Cómo citar este artículo: Ayllón Gutiérrez, I. (2021). Decadencia urbana y clero conventual femenino. Sobre la fundación del Monasterio de Santa Ana de Chinchilla. Al-Basit (66), 279-300. http://doi.org/10.37927/al-basit.66_7

Recibido/Received: 13-02-2021

Aceptado/Accepted: 03-05-2021

RESUMEN: El artículo analiza el monasterio dominico de Santa Ana de Chinchilla (Albacete) durante sus primeras décadas de existencia, despejando errores y dudas vertidas en el único estudio hecho hasta la fecha sobre dicha comunidad. Asimismo profundiza en las relaciones sociales
ABSTRACT: The article analyses the Dominican monastery of Santa Ana in Chinchilla (Albacete) during its first decades of existence, and it clears up errors and doubts which were expressed in the only historical research which have been carried out so far. The study also delves into the social

Este trabajo se inscribe dentro del proyecto de investigación SBPLY/19/180501/000187 Ciudad, economía y territorio en Castilla-La Mancha durante la Baja Edad Media, aprobado por la Consejería de Educación, Cultura y Deportes de la Junta de Comunidades de Castilla-La Mancha, cofinanciado por el Fondo Europeo de Desarrollo Regional y adscrito a la Universidad de Castilla-La Mancha, a desarrollar entre 2020 y 2023.

Abreviaturas: $A D=$ Archivo Dominicano; AGS = Archivo General de Simancas; AHPAb = Archivo Histórico Provincial de Albacete; AHPDA = Archivo Histórico de la Provincia Dominicana de Andalucía (Convento de Santo Tomás, Sevilla); IEA = Instituto de Estudios Albacetenses; OPSEC = La Orden de Predicadores en el sureste de Castilla (libro). 
y económicas establecidas entre la sociedad comarcal y las religiosas del monasterio, el cual vio afectada su supervivencia por la falta de dotación fundacional y por el declive que experimentó la ciudad en la época.

PALABRAS CLAVE: Orden de Santo Domingo (Predicadores), Baja Edad Media, Chinchilla (Castilla), monjas. and economic relationships established between the local society and the monastery nuns, whose survival was affected by the lack of foundational endowment and by the decline that the city suffered during that time.

KEY WORDS: Order of Saint Dominic (Preachers), Late Middle Ages, Chinchilla (Castile), nuns.

En el año 2002 el Instituto de Estudios Albacetenses publicó la obra La Orden de Predicadores en el sureste de Castilla (Las fundaciones medievales de Murcia, Chinchilla y Alcaraz hasta el Concilio de Trento), en la que se efectuaba un primer acercamiento mínimamente detenido a la historia de los conventos dominicos de la actual provincia de Albacete. Aunque desde entonces los estudios historiográficos no han avanzado de una manera decisiva, al menos sí han permitido una ampliación de nuestros conocimientos así como la aparición de nuevos enfoques teóricos. En lo que se refiere a la historiografía local, algunos trabajos han conseguido perfilar con más precisión los pormenores de la evolución política y social de la región comprendida en el mencionado estudio. De igual modo, los títulos centrados en entidades eclesiásticas también han progresado no solo en sus enfoques descriptivos e institucionales, sino en el análisis de las relaciones de las instituciones clericales con el entorno social y político. ${ }^{1}$ Hay que indicar además la importancia

\footnotetext{
${ }^{1}$ Resultaría inabarcable reseñar la cantidad de títulos surgidos a tal respecto. Para un primer acercamiento, aparte de la obra citada (Carlos Ayllón Gutiérrez, La Orden de Predicadores en el sureste de Castilla. Las fundaciones medievales de Murcia, Chinchilla y Alcaraz hasta el Concilio de Trento, IEA, Albacete, 2002), véanse Aurelio Pretel Marín, El señorío de Villena en el siglo XV, IEA, Albacete, 2011; y C. Ayllón Gutiérrez, Iglesia rural y sociedad en la Edad Media, Sílex-IEA, Madrid, 2015. Estos trabajos remiten oportunamente a otros que ayudan a profundizar en la realidad eclesiástica de la Mancha Oriental en el bajo Medievo.
} 
que se ha dado en las últimas décadas al estudio de las comunidades femeninas, como es la que atañe a este pequeño trabajo. En este sentido, intentamos contribuir con la aportación del momento y circunstancias sociales del nacimiento de una de estas comunidades, así como indagar en las relaciones que la comunidad estableció con su entorno social. ${ }^{2}$

\section{ANTECEDENTES}

Una de las comunidades estudiadas en la citada obra es la conformada por las monjas dominicas del monasterio de Santa Ana de Chinchilla, de la que bien poco es lo que se conoce. Sí sabemos que el emplazamiento de su casa conventual se buscó intramuros de la ciudad en la octava década del siglo XV, en el solar de lo que debió de ser una antigua mezquita, junto a un enorme desnivel de terreno. En tal caso, el templo islámico quedó habilitado para el culto cristiano cuando en un incierto momento del siglo XIII se transformó en una pequeña ermita dedicada a Santa Catalina, tal vez derivada de una anterior iglesuela de ayuda parroquial, que en todo caso en el siglo XVI todavía conservaba una suerte de torre alminar «labrada a la morisca» (Carrilero et al., 2014, 90).

Antes de abordar los detalles de su fundación, señalaremos que resulta verosímil que a finales de la centuria del catorce se creara la vicaría de Albacete, que quedó desgajada del arciprestazgo de Chinchilla. Se trataría de una maniobra que consolidaría la segregación de la villa albacetense con respecto a la población matriz, culminada en lo político en noviembre de 1375, en correlación con el auge político albacetense y su acumulación monetaria. Esto hechos pudieron incidir en la necesidad de Chinchilla de recuperar cierta notoriedad en el ámbito religioso, anhelo que se reflejaría en el apoyo de su concejo o del vecindario a la fundación de una casa para

\footnotetext{
${ }^{2}$ Una reciente visión de conjunto y puesta al día de esta temática la tenemos en Ángela Atienza López, Tiempo de conventos: una historia social de las fundaciones en la España moderna, Marcial Pons-Universidad de La Rioja, Madrid, 2008.
} 
frailes de la Orden de Predicadores y erigido en la última década del siglo XIV bajo la advocación de San Juan Bautista (Ayllón, 2015, 287).

Previo al nacimiento de la comunidad dominica masculina ya existía un grupo de monjas de Chinchilla de las que hay noticia en 1386 y que quedan sumidas en el olvido y en un enigma de difícil resolución, si bien todo ello apuntaría a una fundación de religiosas prematuramente abortada. Cuando poco después el convento de frailes predicadores emitía sus primeros balbuceos y necesitaba consolidarse, se produjo la creación de una cofradía de hombres y mujeres promovida en él con su misma titulación de San Juan Bautista. La institución canónica de la hermandad o al menos un reconocimiento de la misma se realizó a instancias de fray Nicolás de Valladolid, Maestro General de la Orden (de obediencia aviñonesa) entre 1394 y su fallecimiento en diciembre de 1397. No obstante, cabe la posibilidad de que esta cofradía constituyese en realidad una comunidad de la orden tercera, tal como se sugiere que sucedió en una congregación dominicana análoga fundada en Orvieto un siglo atrás en honor de Santo Domingo y Santa María (Pretel, 1992, 145, nota 207; Henderson, 1990, 299). ${ }^{3}$

No obstante, en tiempos del marqués de Villena Alfonso de Aragón (1369-1395) existieron en Chinchilla unas monjas, aunque ignoramos a qué orden pertenecían. De acuerdo con los registros de escrituras del marqués, las religiosas eran representadas en los pleitos y cuestiones administrativas por procuradores laicos relacionados con don Alfonso, como Sancho Pérez de Ayna y Asensio Martínez. En el supuesto de que fueran profesas dominicas, en ningún caso recurrieron, como era habitual, a frailes de la misma orden

\footnotetext{
${ }^{3}$ La concesión a los y las cofrades se recoge en un documento en papel muy deteriorado (Véase apéndice documental, I). Sin poder confirmarse su fecha, una posterior nota marginal indica «1397», año coincidente con una escritura «en pergamino (sic) más pequeña espedida en Roma (...); tiene un sello de cera con un crucifijo», tal como describe el inventario hecho para la Desamortización de Mendizábal. AHPAb, Clero, caja 5, n.ํㅜ 17. No obstante, el diploma también podría datarse entre 1391 y 1393, cuando fray Nicolás fuera Maestro Provincial de España.
} 
y población para que las representaran, lo que ayuda a despejar la ya insostenible hipótesis de una temprana fundación conventual masculina de hermanos predicadores. Sin embargo, la comunidad de monjas nunca se consolidó, seguramente por las penosas circunstancias del momento y la falta de ingresos materiales. Según Pilar Gil los padrones de Chinchilla de 1454 registran unas monjas de Santo Domingo, si bien nos permitimos dudar de la existencia de tal comunidad en esa época (Gil García, 1987, 629). Más bien se trataría de una errónea lectura, por «monjes», si es que asumimos el lapsus de denominar así a los frailes de San Juan Bautista, que por entonces estaban plenamente activos, o bien que pudiera existir una efímera comunidad de beatas o terciarias en la ciudad y los padrones las calificaran de monjas.

\section{LA FUNDACIÓN Y LAS FUNDADORAS EN TIEMPOS DE REFORMA}

Pero al acontecer la guerra civil de sucesión las circunstancias cambian profundamente en el reino en general y en el viejo señorío en particular, modificándose las estructuras locales de poder. Es en ese contexto donde se inscribe el origen de la casa de monjas dominicas en la ciudad de Chinchilla. Allí, precisamente en la década de los setenta Guiomar Gómez y su hermana Ana Gómez de la Mota, con el concurso de su madre y alegando que en la ciudad no existía ninguna comunidad de religiosas, iniciaron sus gestiones para pasar a una vida de íntimo fervor religioso constituyendo un beaterio. Si tenemos en cuenta que los terrenos en que se edificó el monasterio eran propiedad de la familia de las hermanas, cabe inferir que estas habilitaron una de sus estancias para hacer en ellas vida de recogimiento aprovechando la contigüidad de la ermita de Santa Catalina de Alejandría. El firme apoyo que los hombres de su familia habían prestado al triunfo militar de Isabel I frente al marqués de Villena y a la Beltraneja, les facilitó la concesión de la citada ermita por parte del obispo Lope de Rivas (fallecido en 1479). Tengamos en cuenta que el levantamiento de la ciudad en favor de Isabel de Trastáma- 
ra se efectuó bajo el liderazgo de Alfonso de la Mota, en unión con varios destacados vecinos, como el bachiller Pedro Sánchez de Belmonte, Juan González de Pina, Juan de Baeza, Pedro Gascón y sus cuñados Miguel Soriano y el bachiller Gil Sánchez Soriano, arcipreste de la ciudad y personaje bien conectado con el cabildo de la Catedral de Murcia. ${ }^{4}$

Se trataba del primer paso para llevar a efecto la institución de un monasterio acogido a la regla de San Agustín y con el hábito de Santo Domingo, como era acostumbrado en este tipo de fundaciones. Poco más tarde, Rodrigo Borja (oficial de Cartagena en tiempos de la donación) como cardenal, vicecanciller de la Iglesia de Roma y nuevo obispo de la sede de Cartagena, confirmó la donación a Guiomar y Ana, quienes quedaron bajo la protección de la Orden de Predicadores (y en concreto de los frailes dominicos de la ciudad), un hecho que agilizaba la transformación del pequeño beaterio en un monasterio de la orden segunda dominica. Finalmente, un breve de Inocencio VIII sancionó —el 24 de octubre de 1489- la fundación del monasterio, para lo que les ratificaba la donación de la ermita, en donde tendrían su templo, y les facultaba para convivir en clausura y observancia (Ripoll, 1732, 55-56). ${ }^{5}$ Muy poco después hemos de situar la elección del título de Santa Ana para el monasterio y la adquisición de una talla de Santa Ana, la Virgen y el Niño góticorenacentista que presidía el altar mayor de la iglesia conventual.

Las beatas partían con la ventaja de haber podido recibir la concesión de la ermita de Santa Catalina, adyacente a su casa, con lo que evitaban vincularse a una parroquia, como en el caso del monasterio de dominicas de Zamora, y de este modo gozarían de una mayor autonomía (Álvarez, 2015, 32).

\footnotetext{
${ }^{4}$ Manuscrito de Pedro Cebrián Martínez de Salas (s. XIX), Biblioteca del Museo de Albacete, Mss 7980.

${ }^{5}$ Véase apéndice documental, II.
} 


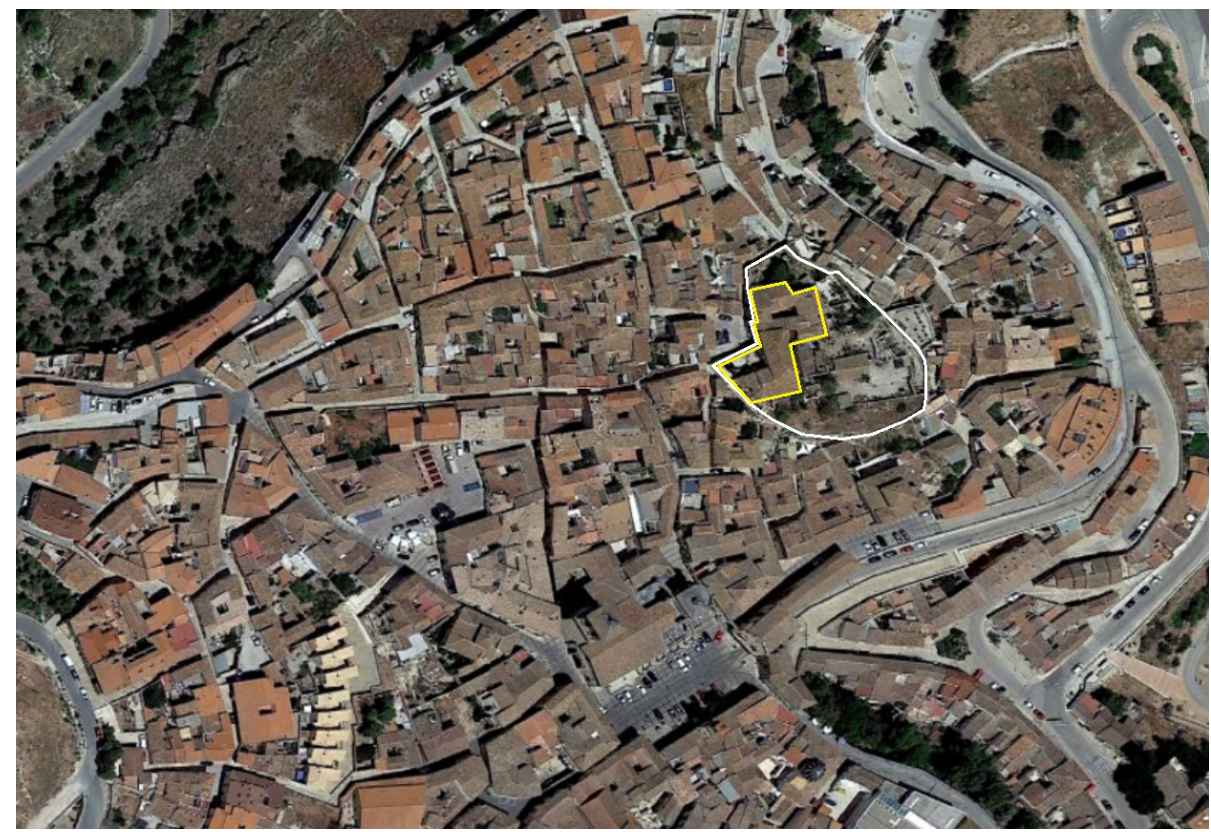

Imagen cenital de Chinchilla (Procedencia: Google Earth). Dentro de la línea exterior se hallarían las casas de la familia De la Mota y el antiguo monasterio de Santa Ana. La línea interior delimita la iglesia conventual, su acceso, el claustro y las celdas de las religiosas.

Entre tanto, el convento de frailes dominicos acogía a una de las comunidades más relajadas de la Orden en toda Castilla. Tras los impulsos reformistas emprendidos en San Pablo de Valladolid, con una rápida respuesta de la mayoría de las casas de la orden, numerosos conventos se incorporaron a la congregación observante, en ocasiones en medio de notables tensiones. Una de las razones de esta reforma y de la tirantez generada, se hallaba en la necesidad que tenían los monarcas de neutralizar la fuerte influencia que los grandes linajes nobiliarios habían ejercido sobre numerosos conventos (Nieva, 2016, 99). En nuestro caso, la reforma era precisa para contrarrestar el ascendiente de los clanes filopachequistas y conversos - Plazuela, Requena, Montealegre-, que habían dado respaldo al convento dominico de San Juan Bautista y facilitado su consolidación.

Es al inicio del siglo XVI cuando la Orden acomete sus últimos intentos de atraer a la reforma interna las pocas casas que 
quedaban por incorporarse a una disciplina más estricta y ejemplar. La transformación de las órdenes recibió un decidido impulso de la reina Isabel y, en el caso de la dominica, también de su Maestro General Vicente Bandello y del Provincial Diego Magdaleno. Lo cierto es que el convento de San Juan Bautista de Chinchilla parece ser en 1508 el último en integrarse en la Congregación de la Observancia, cuando oficialmente la oposición entre reformados y conventuales había concluido dos años atrás. Su influencia debió de sentirse en el claustro femenino de la ciudad. ${ }^{6}$ No obstante, el hecho de que otro convento masculino existiera en la misma población no suponía necesariamente una relación estrecha entre ambas comunidades. Ahora bien, era habitual que en tales casos, los frailes se ocuparan de la representación institucional y de la atención espiritual de las hermanas, proporcionándoles confesores, oficiantes y, cómo no, influencia. Una situación que en realidad interfería en la vida de los religiosos, que se veían sujetos a unas obligaciones no buscadas por ellos.

De la fundadora Ana Gómez de la Mota quedó el recuerdo de una frecuente práctica de la oración en el coro y de estricto ayuno («los siete meses continuos de la orden y todos los viernes y sábados a pan y agua»), acompañado de una obediencia y renuncia, que mantuvo durante toda su vida de profesión y que guarda cierta analogía con movimientos rigoristas de reforma como el que en fechas coetáneas protagonizó la beata de Piedrahita. Es aventurado obtener conclusiones cuando las noticias proceden de las tardías notas de Lorea (f. 23r-v), una fuente en la que los milagros referidos adolecen de sospechosos tintes de exageración y distorsión de los hechos pasados. Es evidente la creación de una leyenda de ejemplaridad forjada en la figura de las hermanas fundadoras, y sin embargo de Guiomar no quedó ninguna imagen modélica para la posteridad,

${ }^{6}$ Hacia esos años fue prior en dos ocasiones en la casa de Chinchilla fray Juan de Gallegos (hermano del capitán Baltasar de Gallegos), procedente del convento de Portaceli de Sevilla, y que también fue prior en Écija. Prestó juramento en el Colegio de San Gregorio en diciembre de 1523 (Hoyos, 1928, 313). Zarpó hacia Florida en 1538 con Hernando de Soto. 
lo que apunta a una especial relevancia de Ana de la Mota, que comparte con la citada religiosa de Piedrahita su carácter de fundadora y posiblemente un talante místico y sensible a revelaciones en las que la beata sostenía pugnas con el propio demonio y sin que el estudio estuviera entre sus prioridades (Pérez Vidal, 2017, 9496). Asimismo, este protagonismo especial puede estar detrás de la advocación a Santa Ana que se dio al convento. Si bien en esos tiempos reformadores se generalizó la dedicación de los monasterios de monjas dominicas a Santa Catalina de Siena (canonizada en 1461), la titularidad escogida por las hermanas de La Mota para nominar su fundación fue la que se correspondía con el nombre de una de ellas - una práctica común de la época-, y tratándose además de la más espiritual de las hermanas. Por lo demás, la supuesta intervención de un elemento sobrenatural en el proceso fundador está presente en la creación de multitud de casas de religión (Miura, 2003, 128). Estas comunidades quedan así fortalecidas y de algún modo santificadas para la sociedad, por lo que el factor legendario de las vivencias milagrosas se difundía bien pronto y con acusada eficacia.

Procedían las fundadoras de un clan de acomodados labradores posteriormente ennoblecidos al haber sido armado caballero el licenciado Andrés de la Mota. Lorea puso especial cuidado de incluir una breve reseña sobre Alonso de la Mota (seguramente hermano de las fundadoras) a la hora de hacer su descripción del convento de San Juan Bautista. Aunque no guardara relación directa con la casa de los frailes, era consciente de la importancia de su estirpe para la Orden de Predicadores en la ciudad. De ahí su encendida semblanza. $^{7}$

[...] tomaron las armas los vecinos de la ciudad y echaron de ella a todos los parciales del marqués, los quales se retiraron al castillo y fortaleza la qual estaba por el Marquesado, y al instante el capitán Alonso de la Mota leuanto los pendones por los Reyes Católicos en la plaza de la ciudad, acción gloriosa, aunque le costó la vida,

\footnotetext{
${ }^{7}$ Antonio de Lorea, Historia de la Provincia de Andalucía de la Orden de Predicadores. Tomo 2, parte 1, AHPDA, Mss. 10-1, f. 21v.
} 
porque los marquesinos (así llamaban a los que seguían el vando del marqués) le cobraron tal odio que no descansaron asta darle la muerte aleuosamente; pues estando descuydado a la puerta de su casa, desde la ventana de otra le tiraron un balazo y priuaron aquella ciudad de el mejor ijo suyo, digno de más vida y más grandes premios. Fue su muerte muy sentida de todos los buenos vasallos de los reyes, y en memoria de auer perdido la vida por tan gloriosa enpresa, le leuantaron una estatua y la colocaron en su capilla que llaman del Santo Cristo en la iglesia mayor de aquella ciudad.

Pese a no ser especialmente hacendadas, las hermanas De la Mota dejaron a la fundación sus casas, adyacentes a la ermita, y sus bienes, pero sin procurarle una dotación sostenida y permanente, lo que supuso un lastre que la convirtió en una comunidad de extrema debilidad económica; tanto que en 1520 los oficiales del concejo suplicaban al emperador Carlos que proporcionara algún tipo de rentas o penas pecuniarias con las que poder subsistir la quincena de monjas que poblaban la comunidad. La misiva la remitían los regidores Diego García de Otazo, Cristóbal de Olivares y Diego Rubio, el jurado Fernando de Castro, y el bachiller Requena, alcalde, agradecido por el apoyo que los dominicos le prestaran en momentos difíciles, como cuando Requena y sus parciales tuvieron que acogerse en 1507 a la protección de los muros del convento al ser acusados por sus vecinos de querer entregar la ciudad al marqués de Villena (Ayllón, 2002, 91). ${ }^{8}$ A ello se vino a añadir la penuria económica del año siguiente, circunstancia que movió al provincial de Andalucía «y de los reynos de Granada y Murçia» a suplicarle también al emperador una ayuda económica para las dos comunidades chinchillanas de la Orden de Santo Domingo, argumentando que en ellas había muchos religiosos y religiosas y por el beneficio que la ciudad obtenía de unos y otras. El provincial le sugirió al monarca que ordenara extraer tal limosna de las rentas y propios municipales. De este modo se emitió una cédula real pidiendo al concejo que obrara en consecuencia, si bien no sabemos cómo reaccionaron los oficiales. ${ }^{9}$

\footnotetext{
${ }^{8}$ AGS, Cámara de Castilla, leg. 137, n. 190 (véase apéndice documental, III). ${ }^{9}$ AHPAb, Municipios, leg. 19, n. ${ }^{\circ} 4$ (Chinchilla, 13-marzo-1522).
} 
La familia de La Mota quedaría desde un principio y en lo sucesivo vinculada a los conventos de dominicos de Chinchilla, ya no sólo por el hecho de que algunos de sus miembros profesen en ellos, sino porque incluso llegarán a fundar patronato sobre algunas capillas de la iglesia conventual de San Juan Bautista ya bien entrada la Edad Moderna. Asimismo, el licenciado Pedro de la Mota, vecino de Villanueva de los Infantes pero seguramente chinchillano de esta familia, regaló en marzo de 1509 a los dominicos de San Juan sendas viñas en el pago del Pozo de Murcia (en el camino al Pozo de la Peña) y en el paraje de Torre Ventosa (Ayllón, 2002, 93). ${ }^{10}$ Cabe pensar además que los 12.000 maravedíes de juro que Alonso de la Mota recibió de Fernando el Católico bien pudieron contribuir a la financiación del monasterio de Santa Ana (Carrilero et al., 2014, 90-91).

Para culminar la fundación femenina, era necesario que concurrieran monjas procedentes de una casa ya instituida, y a tal efecto acudieron varias del convento de dominicas de Nuestra Señora de los Ángeles de Jaén, del cual conviene hacer notar que salieron multitud de religiosas para emprender la fundación de varios monasterios de las áreas meridionales de Castilla. Hasta entonces se puede calificar la casa chinchillana como beaterio, en coincidencia con muchas fundaciones coetáneas, en las que varias mujeres de una misma familia se decidían a hacer vida de oración en común dentro de un espacio doméstico creado por ellas mismas. La incorporación a la Orden segunda se sancionaría oficialmente en ese momento tras asumir la naciente comunidad las Constituciones de Humberto de Romans. Del citado convento giennense saldrían poco después las mismas u otras monjas para efectuar la reforma en las casas de la rama femenina, tal como se venía haciendo en toda la geografía conventual hispana. Existe confusión entre los nombres que corresponden a las fundadoras escogidas por la Orden y a las

${ }^{10}$ Como muestra del vínculo entre la familia y el monasterio, en la segunda mitad del siglo XVII consta la profesión de una María de la Mota, de este oligárquico linaje. Archivo General de Indias, Contratación, leg.436, 5. Esta familia además mantuvo durante siglos casas adyacentes a las dependencias del convento. 
reformadoras. Fray Juan López afirma (1622, 211v) que las fundadoras institucionales fueron las madres Isabel de Mejía (o Messía) y Magdalena de Pallarés, esta última perteneciente a una familia patricia de la ciudad alineada durante la guerra en el bando beltranejista. Tal vez fuera hermana del alcaide García de Pallarés, o acaso sobrina del cura Suero de Pallarés (Pretel, 1992, 375-376, 435), y cabría la posibilidad de que la chinchillana profesara en Jaén y acudiera a su ciudad como nexo idóneo para propiciar la fundación. ${ }^{11}$ Por otra parte, Lorea afirma que las instituidoras fueron esta Magdalena de Pallarés (a la que llama de Villartas) y una tal María Méndez, quienes luego reformaron la casa de Alcaraz, si bien sostiene que las monjas del convento de Jaén que acudieron a Chinchilla a efectuar la reforma fueron la citada Isabel de Mejía e Isabel de Vilches, siendo éstas también quienes reformaron el convento de Linares (López, 1622, $211 v$ ). Deberíamos situar este momento reformador con posterioridad a la emisión del breve Exposuerunt Nobis en marzo de 1493 por parte del papa Alejandro VI a los Reyes Católicos, en el que les otorgaba amplias atribuciones para propiciar la reforma de las religiosas (García Oro, 1980, 277). En cualquier caso, la reforma que experimentó el convento se efectuó a los pocos años de su creación, lo que sin duda supuso una contrariedad para las religiosas que acaso no contaban con el ímpetu reformador y tal vez tenían otros proyectos para la casa. La falta de dinamismo en el despegue de la fundación habría, pues, que buscarla en el desconcierto que las tendencias rigoristas causaron en las familias que pretendían buscar en el monasterio un lugar de destino a algunas de sus féminas.

No tardaría, por lo demás, en acontecer la creación de la Provincia dominica de Andalucía o Bética, en virtud del Breve emitido por el papa León X en 10 de octubre de 1514, en la que se incluyeron las casas de esta área geográfica, aunque también las de Murcia, Ciudad Real, Alcaraz y Chinchilla, que hasta entonces estaban englobadas en la Provincia de España.

\footnotetext{
${ }^{11}$ Existe una sor Isabel de Mejía en Toledo entre 1490 y 1500, hija del canónigo de la Catedral de Toledo Marcos Díaz de Mondéjar y de Catalina Suárez (Barrios, 1997, 190).
} 
Por lo que se refiere a los vínculos sociales establecidos por la comunidad de Santa Ana en sus inicios, no resulta fácil precisarlos, más allá de las relaciones referidas a las religiosas citadas. Parece claro que algunas de las más destacadas familias de cuantas habitaron en Chinchilla y que se adhirieron a las maniobras políticas de los marqueses de Villena, fueron las que proporcionaron un mayor soporte económico a la Orden de Predicadores en Chinchilla, constituyendo entre sí y con la comunidad de frailes una tupida red social.

\section{TRANSFORMACIONES SOCIALES Y DECADENCIA}

Sin embargo, la fundación vino a coincidir con un cambio de coyuntura. La victoria de los Reyes Católicos sobre las tropas de los Pacheco acarreó el declive de muchos de esos clanes alineados junto a los vencidos, entre ellos los viejos leales Plazuela (discretamente alejados en su señorío de Carcelén), los Montealegre (reacomodados en tierras de Murcia) y la familia Requena (que tras la amnistía recibida recuperaron cierto protagonismo, aunque con un perfil bajo y manteniendo sus vínculos con el convento dominico masculino durante el siglo XVI). Frente a ellos, surgieron ciertos linajes insertados en las estructuras dominantes del nuevo Estado de los Reyes Católicos, como los De la Mota, que también se aproximarán a las comunidades dominicas en una suerte de relevo político de benefactores. Así pues, desde este momento se detecta la presencia de familias neo-oligárquicas vinculadas al convento (Ayllón, 2002, 9298). Junto a ellas quedaría la huella de los viejos clanes del bando beltranejista. La sepultura de mármol negro de un Gil Pinar (un muy probable descendiente de Gil Gómez Pinar, antiguo mayordomo de Juan Pacheco y rico hacendado de la ciudad) en el altar mayor del monasterio de Santa Ana, apuntaría en esa dirección.

No se aprecia entre los religiosos un número significativo de miembros procedentes de esas familias preponderantes, un fenómeno aún pendiente de análisis en los conventos de la provincia albacetense; si bien en el caso de las monjas dominicas de Chinchilla 
sí parece que esta dinámica se cumpla con mayor evidencia ya desde los primeros momentos de su andadura.

En un contexto de declive en la ciudad, con una demografía en regresión y una ruina concejil de muy difícil recuperación, las monjas adolecían de dificultades para su despegue. La falta de una dotación fundacional estable lastró durante sus inicios la solvencia económica del monasterio femenino. Este factor dificultaría la atracción de novicias y profesas pertenecientes a familias foráneas con una posición material y social eminente, las cuales optarían por otras casas de mayor excelencia. Tal precariedad impedía que la sociedad chinchillana pudiera contribuir a la mejora del monasterio, si bien en la década de los setenta del siglo XVI, el número de religiosas aumentó a veinticinco monjas, la mayoría de linajes de la ciudad. Esto no impidió que sus rentas anuales no fueran especialmente elevadas, pues por entonces no alcanzaban los cien mil maravedíes, cantidad que el arcipreste Cantos calificaba como «muy poca renta» (Carrilero et al., 2014, 98-99). Este modesto estado de la casa de Santa Ana se prolongaría durante los años siguientes, y todavía en las primeras décadas del XVIII conocemos alusiones a la pobreza continuada del monasterio. Bajo estas premisas los monasterios más humildes difícilmente salían de sus apuros materiales.

Recordemos por último que, paralelamente al convento de dominicas de Chinchilla, nació otro de franciscanas en Albacete merced una iniciativa similar acometida por Marina Álvarez Marco y dos hijas suyas. Esta institución en la pujante villa vecina sin duda vino a generar cierta rivalidad entre ambas casas como lugar de destino para mujeres de algunas destacadas familias de la comarca. Por añadidura, en 1490 se fundó en Murcia el monasterio de monjas dominicas - también intitulado de Santa Ana-, añadiéndose así un nuevo elemento competidor en tal sentido. Lo cierto es que en siglos posteriores no hallamos religiosas en el convento procedentes de familias oligárquicas de la ciudad. En este sentido, el monasterio, concebido como lugar de destino honorable para las mujeres de las élites comarcales, fracasó en el caso de la casa de Santa Ana de Chinchilla. 


\section{A MODO DE BALANCE}

En definitiva, el monasterio de dominicas de Santa Ana de Chinchilla surgió en un momento de profundas transformaciones experimentadas en el seno del reino de Castilla. La guerra de sucesión aupó a algunos clanes que, como los De la Mota, aprovecharon su nueva situación para exhibir su poder y su piedad al objeto de afianzarse dentro de su entorno social. A esta estrategia responde la creación del monasterio de monjas chinchillano. Al mismo tiempo se producía dentro del clero regular hispano un profundo movimiento de reforma, que bien pudo paralizar la pujanza esperada en los primeros años de andadura de la comunidad mendicante femenina. A ello cabe añadir el declive en que entró la ciudad de Chinchilla transcurridas pocas décadas, lo cual sumado a la falta de previsión de las fundadoras para dotar la casa con rentas a perpetuidad, lastró el devenir de la comunidad a lo largo de toda su existencia. 


\section{APÉNDICE DOCUMENTAL}

\section{I \\ ¿1397? ¿junio? ¿julio? [s.l.]}

Reconocimiento de fray Nicolás de Valladolid, Maestro General de la Orden de Predicadores, a la comunidad de hermanos y hermanas congregados en el convento de San Juan Bautista.

AHN, Clero regular-secular, Pergaminos, carpeta 2, no 10 .

PUBL. C. Ayllón Gutiérrez, La Orden de Predicadores en el sureste de Castilla, IEA, Albacete, 2002, p. 152-153 (Al hallarse el original muy deteriorado por rotura, se intenta aquí reconstruir el texto completo tras cotejarlo con otros diplomas análogos. Entre corchetes se hallan los fragmentos ausentes. Pese a no poder confirmarse el contenido exacto de lo perdido, en cursiva se reproducen las partes con menos probabilidad de coincidencia con el original, y en redonda las más verosímiles).

[... et i]n [Dei filio sibi dilectis confratribus et] confratrissis in honorem Beati Johannis Babtiste in domo s[uo Ordinis Fratrum Predicatorum c]ongregatis Cartagenae dyocesis, frater Nicholaus Vallisoletanus, [Magister Generalis Ordinis supradictae...] dignos facere penitencie salutaris.

Contra mundi huius dampnosa discrimin[a, cupientes Beatum Iohann]em Babtistam intercessorem specialissimum et patronum propicium uobis eligere pr[ouide decreuistis, in ipsius honorem, reverentiam et devotionem grat]am Deo congregationem sicut accepimus cum uestrorum cumulo beneficiorum statuentes [ut eius adiuti meritis et intercessio]nibus, donis celestis gracie copiosius impetratis redamini culpe recepta venia [in fide stabiles et in opere eficaces.]

Et ut predicta celerius ac copiosius assequi valeatis, ex parte uestram fuit ad nos f[ideliter ac humiliter supplicatum, u]t fratrum nostrorum, quos Dei creditis domesticos et amicos vos fac[ere]ns bonorum o[mnium communione gaudere...] dos qui ob Dei honorem nec non deuocionem martiris predicti vestris meritis digne [pensa- 
tis, quod memoratos fratr] es nostros ex cordis intimis urgentes eos curatis prossequi fauorabilibus effectib[us operibus pietatis congregationi vestre et ceteris,] qui se uestro pio consorcio duxerint in posterum nostri ordinis Dominus per mundum fier[i dederit vniversum participationem conc] edimus, tenore presentium, specialem in vita pariter et in morte, ut multip[lici suffragiorum presidio et hic augm] entum gracie et in futuro mereamini premium perpetue beatitudinis consequ[i sempiterne.

In cuius concessi]onis testimonium sigillum nostrum duxi presentibus appendendum.

[Datum...] die Julii, anno Domini, Mo CCC nonages[simo septimo...].

\section{II}

\section{9, octubre 24. Roma.}

Bula del papa Inocencio VIII, a súplicas de las hermanas Guiomar y Ana de la Mota, dirigida al deán de Lorca y al oficial de Cartagena dando licencia para fundar en Chinchilla un monasterio de monjas de la Orden de San Agustín que se hallan bajo la protección de la Orden de Predicadores, confirmando concesiones previas.

PUBL. Thomas Ripoll, Bullarium Ordinis FF. [i.e. Fratrum] Prædicatorum, Vol. 4 («Ab anno 1484 ad 1549»), Imp. Jerónimo Mainardi, Roma, 1732, p. 55-56 (Entre corchetes se reproducen las fórmulas que se omiten en la transcripción de esta obra).

Innocentius Episcopus, servus servorum Dei, dilectis filiis Archidiacono de Lorca in Ecclesia Cartaginense et officiali Cartaginensi, salutem et apostolicam benedictionem.

Sedis Apostolice gratiosa benignitas piis fidelium quarunlibet personarum, presertim feminei sexus etc. [sub regulari observantia piae vitae studio famulantium gratum prestamus assensum et ad ea que ipsarum corporum et animarum salutem, nec non divini cultus augmentum respiciunt consequenda libenter interponimus solicitudinis nostre partes, ut sublatis quibusvis dispendiis 
vota sua quietius et securius in humilitatis spiritu altissimo queant impartiri.]

Exhibita siquidem Nobis nuper pro parte dilectarum in Christo filiarum Priorissae et Conventus Monasterii Monialium oppidi de Chinchilla Ordinis Sancti Augustini sub cura Fratrum Praedicatorum degentium, Cartaginensis Dioecesis, petitio continebat, quod cum alias, in dicto Oppido, non esset aliquod Monasterium monialium dicti Ordinis sub huiusmodi cura degentium, et dilectae in Christo filiae Guiomar Gomez et Anna de la Mota ${ }^{12}$ tunc mulieres dicti oppidi, nunc vero eiusdem monasterii moniales, cuperent sub regulari habitu dicti Ordinis virtutum Domino famulari, nonnullas domos in dicto oppido existentes, et eremitorio, sive ecclesia sine cura Sanctae Catherinae, quod intra muros dicti oppidi existit, contiguas, de propriis bonis emerunt, ac postmodum cum eisdem domibus, unum monasterium monialium dicti Ordinis sub eadem cura degentium, de licentia ordinarii loci erectum fuisset, Guiomar et Anna praedictae, habitum per easdem moniales gestari solitum, susceperunt et in eodem Monasterio, professionem regularem, per moniales eiusdem Ordinis sub simili cura degentes emitti solitam, emiserunt regularem et demum Provincialis Provinciae Cartaginensis secundum morem dicti Ordinis, alias moniales de regularibus Institutis Ordinis eiusdem, bene instructas in dictum monasterium introduxit, que una cum Guiomar et Anna praedictis inibi sub perpetua clausura et regulari observantia vixerunt et vivunt et cum magna populi devotio erga easdem moniales crevisset, bonae memoriae Lupus, Episcopus Cartaginensis, dictum Eremitorium, sive Ecclesiam eisdem Monialibus concessit et donavit ac postmodum, tunc officialis Cartaginensis, seu Vicarius venerabilis Fratris nostri Roderici, Episcopi Portuensis Sanctae Romanae Ecclesia Vicecancellarii, Ecclesiae Cartaginensis in spiritualibus et temporalibus perpetui administratoris in eisdem spiritualibus Generalis, habens ad hoc, ut asserebat, ab eodem Roderico Episcopo et administratore especialem per ipsius literas facultatem, ordinaria auctoritate con-

\footnotetext{
${ }^{12}$ El registro indica erróneamente «Velameta».
} 
firmavit et approbavit prout in quibusdam instrumentis publicis, desuper respective confectis, dicitur plenius contineri. Quare pro parte priorissae et Conventus praedictarum Nobis fuit humiliter supplicatum, ut erectioni, concessioni et donationi ac approbationi et confirmationi praedictis, pro illarum subsistentia firmiori, robur Apostolicae confirmations adiicere, aliasque in praemissis opportune providere, de benignitate Apostolica dignaremur.

Nos igitur, qui illis votis, per quae prudentes virgines, accensis lampadibus, Domino obviam ire et integritatem suam, illi qui speciosus est prae filiis hominum, reddere valeant, libenter annuimus, ipsas Priorissam et Conventum ac earum singulas a quibuscunque excommunicationis, suspensionis etc. [et interdictii aliisque ecclesiasticis sententiis, censuris et penis a iure vel ab homine quavis occasione, vel causa latis si quibus quomodolibet innodate existunt, ad effectum praesentium duntaxat consequendum, harum serie absolventes, et] absolutas sore censentes, huiusmodi supplicationibus inclinati discretioni vestrae etc. [per apostolica scripta] mandamus quatenus vos, vel alter vestrum, erectionem, concessionem, donationem ac approbationem et confirmationem praedictas, si et postquam de illis vobis legitime constiterit, auctoritate nostra, sine alicuius praejudicio confirmetis et approbetis, suppleatisque omnes et singulos defectus, si qui foran intervenerint in eisdem, non obstantibus constitutionibus et ordinationibus Apostolicis etc. [ceterisque contrariis] quibuscunque.

Datum Romae apud Sanctum Petrum Anno Incarnationis Dominicae Millesimo Quadrigentesimo Octuagesimo Nono, Nono Kalendas Nouembris, Pontificatus nostri anno Sexto.

\section{III}

\section{0, marzo 11. Chinchilla.}

Solicitud del concejo de Chinchilla al rey Carlos I para que conceda algún tipo de merced o limosna a las monjas de Santa Ana, que viven en la pobreza.

AGS, Cámara de Castilla, leg. 137, no 190. 
El concejo, justiçia, regidores, caballeros, escuderos, ofiçiales, omes buenos de la noble y leal çibdad de Chinchilla besamos las reales manos de Vuestra Magestad y le hasemos saber que en esta çibdad ay un monesterio de monjas de la horden de Santo Domingo, en que ay continuamente quinse monjas, muy buenas mugeres. Biben muy casta y onestamente, hasen mucho fruto en esta çibdad para seruiçio de Nuestro Señor, son pobres, no tienen propios ni rentas de que coman, sino solo el trabajo de sus manos y de Aquel, gosan la menor parte del dia porque residen en el coro todas las oras. Humillemente suplicamos a Vuestra Magestad les faga alguna merçed y limosna en las rentas reales o en las penas fiscales o en lo que vuestra magestad sea más seruido, porque tan onestas y recatadas mugeres no mueran de hanbre; y en esto, señor, Nuestro Señor será dello muy servido y esta çibdad reçebiría muy señalada merçed y las dichas monjas merçed y limosna. Guarde Nuestro Señor la vida y muy poderoso estado de Vuestra Majestad con acresçentamiento de más reinos e señoríos.

Desta çibdad de Chinchilla, XI de março de I $\sqrt{ }$ DXx años.

(Rúbricas:) El bachiller Requena. Diego Garçia de Otaço. Christoual de Oliuares. Fernando de Castro. Diego Ruuio. 


\section{REFERENCIAS BIBLIOGRÁFICAS}

ÁLVAREZ RODRÍGUEZ, A. (2015). De beatas a monjas dominicas: el proceso de constitución del monasterio de Santa Catalina de Sena de Zamora a finales del siglo XV. Hispania, LXXV (249), 11-38. https://doi.org/10.3989/hispania.2015.001

AYLLÓN GUTIÉRREZ, C. (2002). La Orden de Predicadores en el sureste de Castilla. Las fundaciones medievales de Murcia, Chinchilla y Alcaraz hasta el Concilio de Trento, Instituto de Estudios Albacetenses «Don Juan Manuel».

AYLLÓN GUTIÉRREZ, C. (2015). Iglesia rural y sociedad en la Edad Media, Madrid, Sílex- Instituto de Estudios Albacetenses «Don Juan Manuel».

BARRIOS SOTOS, J.L. (1997). Santo Domingo el Real y Toledo a fines de la Edad Media (1364-1507). Instituto Provincial de Investigaciones y Estudios Toledanos.

CARRILERO MARTÍNEZ, R., GARCIA MORATALLA, P.J., CIFO GONZÁLEZ, M., VALDEVIRA GONZÁLEZ, G. (2014). Pueblos de la provincia de Albacete en las relaciones topográficas de Felipe II (Estudio documental, filológico e histórico). Instituto de Estudios Albacetenses «Don Juan Manuel».

GARCÍA ORO, J. (1980). Conventualismo y observancia. La Reforma de las órdenes religiosas en los siglos XV y XVI, en R. GARCÍA VILLOSLADA, (Dir.), Historia de la Iglesia en España, I-3, (pp.211-350). BAC.

GIL GARCÍA, M. P. (1987). La población de Chinchilla a mediados del siglo XV. En Homenaje al profesor Juan Torres Fontes, I, Universidad de Murcia-Academia Alfonso X el Sabio.

HENDERSON, J. M. (1990). Piety and Heresy in Medieval Orvieto: The Religious Life of the Laity, c. 1150-1350, University of Edinburgh.

HOYOS, M.M. (1928). Historia del Colegio de San Gregorio de Valladolid, I. Cuesta. 
LÓPEZ, J. (1622). Quinta parte de la Historia de Santo Domingo y de su Orden de Predicadores. Juan de Rueda.

MIURA ANDRADES, J. M. (2003). Milagros y conventos en la Andalucía medieval, Cuadernos del CEMYR, (11), 113-131. http:// riull.ull.es/xmlui/handle/915/18826

NIEVA OCAMPO, G. (2016). De la colaboración a la oposición: los frailes dominicos y la realeza castellana (1370-1474), Erasmo: Revista de historia bajomedieval y moderna, Universidad de Valladolid.

PÉREZ VIDAL, M. (2017). La liturgia procesional de completas en el ámbito de los monasterios femeninos de la Orden de Predicadores en Castilla. Hispania Sacra, LXIX (139), 81-99. https:// doi.org/10.3989/hs.2017.006

PRETEL MARÍN, A. (1992). Chinchilla medieval. Instituto de Estudios Albacetenses «Don Juan Manuel».

PRETEL MARÍN, A. (2011). El señorío de Villena en el siglo XV. Instituto de Estudios Albacetenses «Don Juan Manuel».

RIPOLL, Th. (1732). Bullarium Ordinis FF. [i.e. Fratrum] Prædicatorum, Vol. 4 («Ab anno 1484 ad 1549»). Hyeronimus Mainardi. 